\title{
Sınıf Öğretmeni Adaylarının Yaşam Boyu Öğrenme Ĕ̆ilimleri
}

\section{Lifelong Learning Tendencies of Primary School Teacher Candidates}

\author{
Ümran ŞAHİN ${ }^{1}$, Emel SARITAŞ² ${ }^{\text {, Gülsüm ÇATALBAŞ }}{ }^{3}$ \\ ๑) Geliș Tarihi: 10.06.2019 @ Kabul Tarihi: 02.10.2019 @ Çevrimiçi Yayın Tarihi: 02.10.2019
}

\section{$\ddot{\mathbf{O} z}$}

$\mathrm{Bu}$ araştırmada sınıf öğretmeni adaylarının yaşam boyu öğrenme eğilimlerinin cinsiyet, mezun oldukları lise türü, kurslara katılma durumları ile katıldıkları kurs türü değişkenlerine göre değişip değişmediğini belirlemek amaçlanmıştır. Araştırma tarama modellerinden olan genel tarama modeli ile gerçekleştirilmiştir. Araştırma verileri Diker Coşkun (2009) tarafından geliştirilen "Yaşam Boyu Öğrenme Eğilimleri Ölçeği" ile elde edilmiştir. Araştırma bulgularına göre sınıf öğretmeni adaylarının yaşam boyu öğrenme eğilim puanları ölçek ortalama puanın üzerinde çıkmıştır. Cinsiyet değişkenine göre kadın ve erkek öğretmen adaylarının yaşam boyu öğrenme eğilimleri arasında kadın öğretmen adayları lehine anlamlı farklılık olduğu gözlenmiştir. Mezun olunan lise türüne göre anlamlı bir farklılık görülmezken, kurslara katılım durumları incelendiğinde, kursa katılan öğretmen adaylarının yaşam boyu öğrenme eğilim puanlarının daha yüksek olduğu görülmüştür. Fakat kurs türüne göre öğretmen adaylarının yaşam boyu öğrenme eğilim puanlarında anlamlı bir farklılık bulunmamıştır.

Anahtar sözcükler: sınıf öğretmeni adayı, yaşam boyu öğrenme, yaşam boyu öğrenme eğilimi

Atıf:

Şahin, Ü., Sarıtaş, E. ve Çatalbaş, G. (2020). Sınıf öğretmeni adaylarının yaşam boyu öğrenme eğilimleri. Pamukkale Üniversitesi Eğitim Fakültesi Dergisi, 48, 374-389.doi: 10.9779/pauefd.572500

\footnotetext{
${ }^{1}$ Dr. Öğrt. Üyesi, Pamukkale Üniversitesi, Eğitim F. Temel Eğitim Böl. usahin@ pau.edu.tr. 0000-0001-5214-0417.

2 Dr. Öğrt. Üyesi, Pamukkale Üniversitesi, Eğitim F. Temel Eğitim Böl. esaritas@ pau.edu.tr. 0000-0002-0101-4987

3 Dr. Öğrt. Gör., Pamukkale Üniversitesi, Eğitim F. Eğitim Bil. Böl. catalbas@ pau.edu.tr. 0000-0001-6971-1079
} 


\begin{abstract}
This study aimed to reveal whether the lifelong learning tendencies of primary school teacher candidates differed in terms of gender, the type of high school they graduated, their participation in courses and the type of course they attended. The research was carried out through the general survey model, which is one of the survey models. The data of the study were collected through the "Lifelong Learning Tendency Scale" developed by Diker Çoşkun (2009). According to the results of the research, the lifelong learning tendency scores of the teacher candidates were above the mean score of the scale. In the study, the lifelong learning tendencies of the primary school teacher candidates were compared in terms of different variables. While the lifelong learning tendencies of primary school teacher candidates differed by gender, no significant difference was revealed in terms of the type of high school they graduated. It was also concluded that the lifelong learning tendencies of primary school teacher candidates differed by their participation in various courses. This difference was found to be in favour of the candidates participating in courses. However, the lifelong learning tendencies of primary school teacher candidates did not differ by the type of the course they attended.
\end{abstract}

Keywords: primary school teacher candidate, lifelong learning, lifelong learning tendency

\title{
Cited:
}

Şahin, Ü., Sarıtaş, E. ve Çatalbaş, G. (2020). Lifelong learning tendencies of primary school teacher candidates. Pamukkale Üniversitesi Eğitim Fakültesi Dergisi, 48, 374-389.doi: 10.9779/pauefd.572500 


\section{Giriş}

Dünya 20. yüzyıldan itibaren davranışçı ekole dayanan nesnel bilgilerin birey tarafından ezberlenmesini öngören öğrenme biçimini terk ederek yapılandırmacı ekolün öngördüğü bilginin öznelleştirilerek öğrenilmesini vurgulayan anlayışı benimsemiştir. Günümüz bilgi toplumunun en önemli özelliklerinden biri öğrenme becerisine sahip bireylere ihtiyaç duyulmasıdır. Öğrenme, kişilerin yalnızca mesleki kariyerlerine katkıda bulunan, çocukluk ve gençlik dönemleriyle sınırlı bir faaliyet değildir. Öğrenme, kişilerin doğumundan ölümüne kadar, yaşamlarının bütün dönemlerini kapsayan bir süreçtir. Yaşam boyu öğrenme, bu anlayışın bir sonucu olarak, öğrenmeyi "Beşikten mezara" kadar uzanan kesintisiz faaliyet olarak gören bir yaklaşımdır (Commission of Europan Comminities 2000; Gündoğan, 2003).

Yaşam Boyu öğrenme kavramı ilk olarak İngiltere'de 1919 yılında Eğitim Yasası'nda yer alır ancak daha açık ve kapsamlı olarak 1972 yılında United Nations Educational, Scientific and Cultural Organization'ın (UNESCO) "Eğitimin gelişimi ile ilgili Uluslararası Komisyon Raporunda yer almıştır (Field 2001; Parker, 2003). Faure, Herrera, Kaddaura, Lopes, Petrovsky, Rahnema ve Ward tarafindan hazırlanan ve Faure Raporu olarak adlandırılan bu raporda hem gelişmiş hem de gelişmekte olan ülkelerin eğitim politikaları için ana kavram olarak "yaşam boyu eğitim" önerilmiştir. Eğitime ilişkin görüşlerin 20 ilkede açıklandığı bu raporda ilk olarak yaşam boyu öğrenme, öğrenen toplumun temel taşı olarak ifade edilmiş ve her bireyin yaşam boyu öğrenmeye devam etmesinin gerekliliği vurgulanmıştır. Raporda öğrenmenin zaman ve mekândan bağımsız olması gerektiği, tamamıyla açık bir sistemde öğrenenlere yatay ve dikey olarak hareket etmeleri sağlandığında öğrenmek için daha fazla seçeneğin sunulabileceği ifade edilmiştir. Eğitimin gençleri sürekli gelişime ve değişime, üretime ve şartlara alışmaya hazırlaması ve bunun için genel eğitim kavramının genişletilmesi ve yeni bir eğitim anlayışının oluşturulması gereklidir. Oluşturulan bu yeni eğitim anlayışında, birey kendi kültürel gelişiminin yaratıcısı olmalıdır. Kendi kendine öğrenme, özellikle de yardımlı kendi kendine öğrenme bütün eğitim sistemlerinde değişmez bir değere sahiptir. Toplumsal ve ekonomik teknik ve pratik bilgiyi içerecek bir eğitim anlayışında yaşam boyu öğrenme ile iş, endüstri ve tarım şirketlerinin de kapsamlı bir eğitimsel işlevinin olacağı ifade edilmiştir (Faure ve ark, 1972). UNESCO'nun yanında 1973 y1lında Organization for Economic Cooperation and Development (OECD) tarafından "Yaşam Boyu Öğrenme İçin Bir Strateji "adlı raporda da yaşam boyu öğrenmenin gerekliliği vurgulanmıştır (Güngör, 2007) .

UNESCO 1972 yılındaki yaşam boyu ilkelerine 1996 y1lında yaşam boyu öğrenme hedeflerini eklemiştir. Avrupa Birliği de 1996 yılını yaşam boyu öğrenme yılı olarak açıklamıştır. Bu yılın üç ana amacı vardır; birinci amacı yaşam boyu öğrenme kavramını teşvik etmek, ikinci amacı anlam ve özelliklerini açıklamak, üçüncüsü ise bütün Avrupa vatandaşları için bu kavramın bir gerçeklik olabilirliğini gözden geçirmektir (Chien, 1996, Akt: Diker Coşkun ve Demirel, 2012). Avrupa Komisyonu tarafından 2000 yılında Yaşam Boyu Öğrenme Memorandumu yayımlanarak yaşam boyu öğrenmenin kapsamı açıklanmıştır. Bu memorandumda üye ülkelerle birlikte, aday ülkeler ve Avrupa Ekonomik Bölgesi Üyelerinin katılımıyla yaşam boyu öğrenme konusunda bir müzakere başlatmak amaçlanmıştır. Memorandumda yaşam boyu öğrenme; herkes için yeni beceriler, insan kaynaklarına yatırım, öğretme ve öğrenmede yenilik, öğrenmeye değer verme, rehberlik ve danışmanlığın yeniden 
değerlendirilmesi, öğrenmeyi eve daha yakın hale getirme olmak üzere altı anahtar mesaj üzerinde açıklanmıştır. Bu çerçevede yaşam boyu öğrenme; kişisel, toplumsal, sosyal ve/veya iş yaşamı perspektifinde bilgi, beceri ve yetilerin geliştirilmesi amacıyla yapılan, bütün amaçlı öğrenme etkinliklerini kapsayan geniş bir kavramdır. Bu etkinlikler örgün, yaygın ya da doğal öğrenme sürecinde gerçekleşebilir (Commission Of The European Communities, 2000). Yaşam Boyu öğrenme alanı Avrupa Birliği tarafindan 2001, 2002, 2005, 2006 ve 2014 yıllarında yapılan zirvelerle tartışılmış ve eğitim politikalarında yerini almıştır.

Yaşam boyu öğrenme kavramı Türkiye'de ise ilk olarak 1960 y1lında toplanan OECD ülkelerinin aldığı kararlar doğrultusunda yer almıştır. OECD'nin hazırladığı raporda yaşam boyu öğrenme küresel ekonomi ve rekabet ortamında mesleki hareketlilik ve bireysel öğrenme olarak belirtilmiştir (Devlet Planlama Teşkilatı, 2001). MEB (2009) tarafından yayımlanan Türkiye Hayat Boyu Öğrenme Stratejisi belgesinde de yaşam boyu öğrenme Avrupa Komisyonunun 2000 yılında yapmış olduğu tanımda ifade edildiği gibi "kişisel, toplumsal, sosyal ve istihdam ile ilişkili bir yaklaşımla bireyin; bilgi, beceri, ilgi ve yeterliliklerini geliştirmek amacıyla hayatı boyunca katıldığı her türlü öğrenme etkinlikleri olarak tanımlanmıştır.

Yaşam boyu öğrenme mesleki gelişim ile beraber ortaya çıkmış bir kavramdır ancak günümüzde öğrenmede sürekliliği ifade etmektedir. Öğrenmeyi öğrenme ve yaşam boyu becerilerini gerçekleştirecek olanlar ise öğretmenlerdir. Öğretmenler hem bu sürecin içinde olacaklar hem de öğretmenlerin kendi yaşam boyu öğrenme yeterlikleri ön plana çıkmaktadır. Selvi'ye (2011) göre öğretmenlerin yaşam boyu öğrenme yeterlikleri, mesleki gelişimlerine yönelik beceriler ve öğrencilerinin yaşam boyu öğrenen bireyler olmalarındaki sorumluluk ve rollerini kapsayacak şekilde iki yeterlik alanına sahip olmaları gerektiğini belirtmiştir. Dolayısıyla öğretmenlerin bu yeterliklere sahip olabilmesi öncelikle aldıkları üniversite eğitimi yani mesleki eğitim süreçlerine bağlıdır. Özellikle çocuklarda öğrenme merakını ve heyecanını ilk uyandıracak ve geliştirecek olan sınıf öğretmenlerinin yaşam boyu öğrenme becerilerine sahip olmaları ayrı bir önem taşımaktadır. Literarürde öğretmenlerin yaşam boyu öğrenme becerilerinin önemli olduğuna dair birçok çalışma mevcuttur (Yılmaz, 2016; Kılıç ve Tuncel, 2014; Epçaçan, 2013; Karakuş, 2013; Arcuria, 2011; Rausch, 2003). Günümüzde öğretmenlik, ülkelere göre statü ve saygınlığı değişmekle beraber özel bilgi ve beceri gerektiren bir meslek olarak kabul görmektedir. Öğretmenlik doğrudan doğruya bireyi merkeze alan bir meslek olması yönüyle, geçmişten günümüze sadece bir kazanç kapısı olarak değil, kutsal bir meslek olarak sayılmaktadır. Türk eğitim tarihine de bakıldığında öğretmenlerin her zaman saygın bir konumu olmuş ve öğretmen denildiğinde toplumda örnek davranışlara sahip bir birey ortaya çıkmaktadır (Şişman ve Acat, 2003). Öğretmenlerin beklenen örnek davranış modeline sahip olması günümüzde yaşam boyu öğrenme becerilerine sahip olmasına da bağlıdır. Bu çalışmanın amacı da sınıf öğretmeni adaylarının yaşam boyu öğrenme eğilimlerinin cinsiyet, mezun oldukları lise türü, kurslara katılma durumları ile katıldıkları kurs türü değişkenlerine göre değişip değişmediğini ortaya koymaktır. Bu amaçla şu alt problemlere cevap aranmıştır:

1. Sınıf öğretmeni adaylarının yaşam boyu öğrenme eğilimleri hangi düzeydedir?

2. Sınıf öğretmeni adaylarının yaşam boyu öğrenme eğilimleri cinsiyetlerine göre değişmekte midir? 
3.Sınıf öğretmeni adaylarının yaşam boyu öğrenme eğilimleri mezun oldukları lise türüne göre değişmekte midir?

4. Sınıf öğretmeni adaylarının yaşam boyu öğrenme eğilimleri kurslara katılma durumlarına göre değişmekte midir?

5. Sınıf öğretmeni adaylarının yaşam boyu öğrenme eğilimleri kurs türüne göre değişmekte midir?

\section{Yöntem}

Araştırma tarama modellerinden olan genel tarama modeli ile gerçekleştirilmiştir. Tarama modelleri, geçmişte ya da halen var olan bir durumu var olduğu şekliyle betimlemeyi amaçlayan araştırma yaklaşımlarıdır. Araştırmaya konu olan olay, birey ya da nesne, kendi koşulları içinde ve olduğu gibi tanımlanmaya çalışılır. Genel tarama modelleri ise bir evrene genelleme yapmak için evrenin tümü ya da evrenden alınan bir örneklem grubu ile yapılan tarama çalışmalardır (Karasar, 2007).

\section{Evren ve Örneklem:}

Araştırmanın evrenini Pamukkale Üniversitesi Eğitim Fakültesi Sınıf Eğitimi Anabilim dalında öğrenim görmekte olan 155 dördüncü sınıf öğrencisi oluşturmaktadır. Evrenin tümüne ulaşılmaya çalışılmıştır. Geçersiz olan anketler çıkarılarak kalan 141 öğrenci ile çalışma gerçekleşmiştir.

\section{Veri Toplama Aracı:}

Araştırmanın verileri Diker Çoşkun (2009) tarafindan geliştirilen "Yaşam Boyu Öğrenme Eğilimleri Ölçeği" ile elde edilmiştir. Ölçek kişisel bilgiler ve ölçek maddeleri olmak üzere iki bölümden oluşmaktadır. 27 maddeden oluşan ölçek maddelerinin yanıtları "çok uyuyor", "kısmen uyuyor", “çok az uyuyor", "çok az uymuyor", "kısmen uymuyor", "hiç uymuyor" şeklinde likert tipinde derecelendirilmiştir. Ölçeğin Croanbach alpha güvenirlik katsayısı bu çalışma için yeniden hesaplanarak. 89 olarak bulunmuştur. Ölçek; motivasyon, sebat, öğrenmeyi düzenlemede yoksunluk ve merak yoksunluğu olmak üzere 4 alt boyuttan oluşmaktadır.

\section{Verilerin Analizi}

Sınıf öğretmeni adaylarının yaşam boyu öğrenme eğilimlerinin belirlenmesinde toplam ortalama puanlar ve standart sapmalar ile ölçekten alınabilecek minumum, orta ve maksimum puanlar ölçüt olarak alınmıştır. Ölçek orta puanı belirlenirken Kolmogorov smirnov testi yapılarak (p>.05) ölçekten elde edilen sonuçların dağılımının homojen olduğu sonucuna ulaşılmıştır. Yaşam boyu öğrenme ölçeğinin boyutları sırasıyla motivasyon (6 madde), sebat (6 madde), öğrenmeyi düzenlemede yoksunluk (6 madde) ve merak yoksunluğu (9 madde) olarak belirlenmiştir. Ölçekte toplam 27 madde bulunmaktadır. Ölçeğin genel ortalamasında ölçekten alınabilecek minimum puan (27x1) 27, ortanca puanı $(27 \times 3,5)$ 94,5 ve maksimum puan $(27 \times 6)$ 162 olarak belirlenmiştir. Ölçekten alınan ortalama puanların değişkenlere göre karşılaştırılmasında t-testi kullanılmıştır. 


\section{Bulgular}

\section{Birinci Alt Probleme İlişkin Bulgular}

Araştırmanın birinci alt probleminde "Sınıf öğretmeni adaylarının yaşam boyu öğrenme eğilimleri hangi düzeydedir?” sorusuna cevap aranmıştır. Sınıf öğretmeni adaylarının yaşam boyu öğrenme eğilim düzeylerine ilişkin genel bulgular Tablo 1'de verilmiştir.

Tablo 1. Sınıf Öğretmeni Adaylarının Yaşam Boyu Öğrenme Eğilim Düzeyleri

\begin{tabular}{lccccccl}
\hline & $\mathrm{N}$ & $\square$ & Ss & Min & Max. & Ortalama & Eğilim Düzeyi \\
\hline Toplam & 141 & 120,65 & 0,826 & 71 & 159 & 4,47 & $\begin{array}{l}\text { KISMEN } \\
\text { UYUYOR }\end{array}$ \\
$\begin{array}{llccccc}\text { Motivasyon } \\
\text { Sebat }\end{array}$ & 141 & 31,63 & 0,611 & 12 & 36 & 5,27 & $\begin{array}{l}\text { ÇOK } \\
\text { UYUYOR }\end{array}$ \\
$\begin{array}{l}\text { Öğrenmeyi } \\
\text { düzenlemede } \\
\text { yoksunluk }\end{array}$ & 141 & 28,11 & 0,784 & 11 & 36 & 4,68 & $\begin{array}{l}\text { KISMEN } \\
\text { UYUYOR }\end{array}$ \\
$\begin{array}{l}\text { Merak } \\
\text { yoksunluğu }\end{array}$ & 141 & 24,23 & 1,439 & 6 & 36 & 4,03 & $\begin{array}{l}\text { ÇOK AZ } \\
\text { UYUYOR }\end{array}$ \\
\hline
\end{tabular}

Ölçekten alınan puanlar incelendiğinde, ölçekten alınan toplam puanlarda en düşük puanın (71,00), en yüksek puanın (159) olduğu görülmüştür. Sınıf öğretmeni adaylarının ölçekten aldıkları puanların ortalamasının ise $\square=120,65$ olduğu görülmektedir. Elde edilen ortalama, ölçek orta puanının (94.5'un) 26,15 puan üstündedir. Bu sonuca göre sınıf öğretmeni adaylarının yaşam boyu öğrenme eğilimleri içinde oldukları söylenebilir. Ölçeğin alt boyutlarının puan ortalamaları incelendiğinde motivasyon alt boyutunun ortalaması $(\square=31,63)$, sebat alt boyutunun ortalamas1 ( $\square=28,11$ ), yoksunluk alt boyutunun ortalamas1 ( $\square=24,23$ ) ve merak yoksunluğu alt boyutunun ortalamasının $(\square=36,67)$ olduğu görülmektedir. Alt boyutlara göre incelendiğinde motivasyon-çok uyuyor, sebat-kısmen uyuyor, yoksunluk-çok az uyuyor, merak yoksunluğu-çok az uyuyor düzeyindedir. Bu sonuçlara göre öğretmen adaylarının öğrenmeye yönelik motivasyonları açısından eğilimlerinin yüksek öğrenmeyi düzenlemede ve merak etmede eğilimlerinin düşük olduğu söylenebilir.

\section{İkinci Alt Probleme İlişkin Bulgular}

Araştırmanın ikinci alt problemi "Sınıf öğretmeni adaylarının yaşam boyu öğrenme eğilimleri cinsiyete göre değişmekte midir?" şeklinde belirtilmiştir. Cinsiyet değişkenine göre sınıf öğretmeni adaylarının yaşam boyu öğrenme eğilimleri arasında anlamlı bir farklılığın olup olmadığına yönelik elde edilen veriler Tablo 2'de gösterilmiştir. 
Tablo 2. Sınıf Öğretmeni Adaylarının Yaşam Boyu Öğrenme Eğilimlerinin Cinsiyet Değişkenine İlişkin t-Testi Sonucu

\begin{tabular}{llllll}
\hline Gruplar & $\mathrm{N}$ & $\square$ & Ss & $\mathrm{T}$ & $\mathrm{p}$ \\
\hline Kadın & 89 & 123,65 & 21,46 & 2,118 & $.036^{*}$ \\
Erkek & 52 & 115,50 & 23,00 & & \\
\hline
\end{tabular}

$* \mathrm{p}<.05$

Tablo 2'deki veriler incelendiğinde kadın ve erkek öğretmen adaylarının yaşam boyu öğrenme eğilimleri arasında anlamlı farklılık olduğu gözlenmektedir. Elde edilen verilere göre kadın öğretmen adaylarının yaşam boyu öğrenme eğilimlerinin $(\square=123,65)$, erkek öğretmen adaylarının yaşam boyu öğrenme eğilimlerinden $(\square=115,60)$ daha yüksek olduğu görülmüştür.

\section{Üçüncü Alt Probleme İlişskin Bulgular}

Araştırmanın üçüncü alt problemi "Sınıf öğretmeni adaylarının yaşam boyu öğrenme eğilimleri mezun oldukları lise türüne göre değişmekte midir?" olarak belirlenmiştir. Bu alt probleme cevap aramak amaciyla Tablo 3 'te mezun olunan lise türüne göre aritmetik ortalama ve standart sapma puanları yer almaktadır.

Tablo 3. Sınıf Öğretmeni Adaylarının Yaşam Boyu Öğrenme Eğilimlerinin Mezun Oldukları Lise Türü Değişkenine İlişkin İstatistik Sonuçları

\begin{tabular}{llll}
\hline Lise türü & $\mathrm{N}$ & $\square$ & Ss \\
\hline Anadolu Lisesi & 57 & 123,02 & 20,698 \\
Düz Lise & 50 & 120,50 & 23,891 \\
Fen Lisesi & 23 & 117,13 & 21,988 \\
Anadolu Öğretmen Lisesi & 11 & 11 & 25,161 \\
Toplam & 141 & 120,65 & 22,318 \\
\hline
\end{tabular}

Tablo 3 'te de görüldüğü gibi araştırmaya katılan 141 sınıf öğretmeni adayının 57'si Anadolu Lisesi, 50'si Düz Lise, 23'ü Fen Lisesi, 11'i de Anadolu Öğretmen Lisesi’nden mezun olmuşlardır. Tablo 4'te mezun olunan lise türüne göre yaşam boyu öğrenme eğilimlerine ilişkin ANOVA sonuçları verilmiştir.

Tablo 4. Sınıf Öğretmeni Adaylarının Yaşam Boyu Öğrenme Eğilimlerinin Mezun Oldukları Lise türüne Göre One way ANOVA Sonuçları

\begin{tabular}{llllll}
\hline & Kareler Toplamı & sd & $\square$ & F & P \\
\hline Gruplar arası & 807,633 & 3 & 269,211 &, 535 &, 659 \\
Gruplar içi & 68926,637 & 137 & 503,114 & & \\
Toplam & 69734,270 & 140 & & & \\
\hline
\end{tabular}

p>.05

Tablo 4'te görüldüğü gibi göre sınıf öğretmeni adaylarının yaşam boyu öğrenme eğilimlerinin mezun oldukları lise türüne göre anlamlı bir farklı1ık çıkmamasına karşın, yaşam boyu öğrenme eğiliminde en yüksek ortalamayı $(\square=123,02)$ Anadolu Lisesi mezunu sınıf öğretmeni adayları, 
en düşük ortalamayı ( $\square=116,36)$ Anadolu Öğretmen Lisesi mezunu sınıf öğretmeni adayları oluşturmaktadır. Ancak ortalamaların birbirine çok yakın olması nedeniyle mezun olunan lisenin yaşam boyu öğrenme eğiliminde etkisi olmadığı söylenebilir.

\section{Dördüncü Alt Probleme İlişkin Bulgular}

Araştırmanın dördüncü alt problemin de ise "Sınıf öğretmeni adaylarının yaşam boyu öğrenme eğilimleri kurslara katılıp katılmadıklarına göre değişmekte midir?" sorusuna cevap aranmıştır. Tablo 5 'te öğretmen adaylarının kursa katılma durumuna göre yaşam boyu öğrenme eğilimlerine ilişkin toplam eğilim puanları, standart sapmaları ve t testi sonucu yer almaktadır.

Tablo 5. Sınıf Öğretmeni Adaylarının Kurslara Katılma Durumlarının t-testi Sonuçları

\begin{tabular}{llllll}
\hline & $\mathrm{N}$ & $\square$ & $\mathrm{Ss}$ & $\mathrm{t}$ & $\mathrm{p}$ \\
\hline Evet & 76 & 125,83 & 20,911 & 3,370 & .001 \\
Hayır & 65 & 113,44 & 22,380 & & \\
Toplam & 141 & & & & \\
\hline $\mathrm{P}<.05$ & & & & &
\end{tabular}

Tablo 5'e göre sınıf öğretmeni adaylarının kişisel ve mesleki gelişimleriyle ilgili kurslara katılma durumları ile yaşam boyu öğrenme eğilimleri arasında anlamlı farklılık çıkmıştır. Farklı kurslara katılan sınıf öğretmeni adaylarının ortalamalarının $(\square=125,83)$ kursa katılmayan sınıf öğretmeni adaylarının ortalamalarından $(\square=113,44)$ daha yüksek olduğu sonucuna ulaşılmıştır. Örgün eğitim hayatları dışında farklı kurslara katılma durumunun sınıf öğretmeni adaylarının yaşam boyu öğrenme eğilimlerine olumlu etkisinin olduğu söylenebilir.

\section{Beşinci Alt Probleme İlişkin Bulgular}

Araştırmanın beşinci alt problemi ise "Sınıf öğretmeni adaylarının yaşam boyu öğrenme eğilimleri katıldıkları kurs türüne göre değişmekte midir?” şeklinde idi. Bu alt problemde farklı kurslara katılan sınıf öğretmeni adaylarının hangi kurslara katıldıkları belirlenmiştir. Katıldıkları kurs türleri ise araştırmacılar tarafından kişisel gelişim, mesleki gelişim ve her iki alana da girenler(kişisel gelişim ve mesleki gelişim) olmak üzere sınıflandırılmıştır. Gitar, bağlama gibi enstrüman çalmayı öğrenmeye yönelik kurslar, sanat içerikli kurslar, tenis, basketbol gibi spor içerikli kurslar kişisel gelişim amaçlı kursların içine alınmıştır. İşaret dili, İngilizce, diksiyon, bilgisayar, drama kursları ise mesleki gelişim kursları olarak değerlendirilmiştir. Tablo 6'da sınıf öğretmeni adaylarının katıldıkları kurs türlerine göre yaşam boyu öğrenme eğilimlerine ilişkin toplam eğilim puanları, standart sapmaları yer almaktadır.

Tablo 6. Sınıf Öğretmeni Adaylarının Katıldıkları Kurs Türleri

\begin{tabular}{llll}
\hline & N & $\square$ & Ss \\
\hline Kişisel Gelişim & 35 & 121,46 & 19,497 \\
Mesleki Gelişim & 32 & 129,44 & 20,348 \\
Hem kişisel hem mesleki gelişim & 9 & 134,44 & 22,667 \\
Toplam & 76 & 126,36 & 20,528 \\
\hline
\end{tabular}


Tablo 6'da görüldüğü gibi, kurslara katıldığını belirten $(\mathrm{N}=76)$ öğretmen adaylarından $35^{\prime} \mathrm{i}$ kişisel ve mesleki gelişim yönelik kurslara, 32'si mesleki gelişimleriyle ilgili kurslara, 9'u da hem kişisel hem de mesleki gelişimleriyle ilgili kurslara katıldıklarını belirtmişlerdir. Beşinci alt problemde de 76 öğretmen adayının hangi kurslara katıldıkları ve bu kursların onların yaşam boyu öğrenme eğilimlerinde farklılık oluşturup oluşturmadığına bakılmıştır. Hem mesleki hem de kişisel gelişim kurslarına katıldıklarını-ifade eden öğretmen öğretmen adaylarının yaşam boyu öğrenme eğilim puanları $(\square=134,44)$ mesleki gelişim kurslarına katılanların ortalama puanlarından ve $(\square=129,44)$ ve kişisel gelişim kurslarına katılanların ortalama puanlarından $(\square=121,46)$ daha yüksektir. Sınıf öğretmeni adaylarının katıldıkları kurs türlerine göre yaşam boyu eğilim puanlarının farklılaşıp farklılaşmadığına ilişkin ANOVA sonuçları Tablo 7'de verilmiştir.

Tablo 7. Sınıf Öğretmeni Adaylarının Yaşam Boyu Öğrenme Eğilimlerinin Katıldıkları Kurs Türüne Göre One Way ANOVA Sonuçları

\begin{tabular}{llcccc}
\hline & Kareler Toplamı & sd & $\square$ & F & p \\
\hline Gruplar arası & 1732,625 & 2 & 866,312 & 2,117 & .128 \\
Gruplar içi & 29870,783 & 73 & 409,189 & & \\
Toplam & 31603,408 & 75 & & & \\
\hline
\end{tabular}
p>.05

Tablo 7 incelendiğinde katıldıkları kurs türüne göre sınıf öğretmeni adaylarının yaşam boyu öğrenme eğilimlerinin anlamlı bir farklılık göstermediği görülmektedir. Sınıf öğretmeni adaylarının kurslara katılmaları yaşam boyu öğrenme eğilimlerini olumlu yönde etkilerken, katıldıkları kurs türü eğilimlerini etkilememektedir.

\section{Tartışma ve Sonuç}

$\mathrm{Bu}$ araştırmada sınıf öğretmeni adaylarının yaşam boyu öğrenme eğilimlerinin belirlenmesi ve bu eğilimlerinin çeşitli değişkenlere göre farklılık gösterip göstermediğini ortaya çıkarmak amaçlanmıştır. Sınıf öğretmeni adaylarının yaşam boyu öğrenme eğilimleri motivasyon, sebat, öğrenmeyi düzenlemede yoksunluk ve merak yoksunluğu olmak üzere dört alt boyutta incelenmiştir. Araştırma sonucuna göre sınıf öğretmeni adaylarının yaşam boyu öğrenme eğilim puanları ölçek ortalama puanın üzerinde çıkmıştır. Buna göre sınıf öğretmeni adaylarının genel olarak yaşam boyu öğrenme eğilimleri içerisinde oldukları söylenebilir. Bu sonuç Demirel ve Akkoyunlu'nun (2010) öğretmen adaylarının yaşam boyu öğrenme eğilimlerini inceledikleri araştırmalarında, öğretmen adaylarının yaşam boyu öğrenme eğilimlerinin yüksek düzeyde olduğu bulgusuyla örtüşmektedir. Yine Şahin, Akbaşlı ve Yanpar Yelken (2010) ile Gencel'in (2013) öğretmen adaylarının yaşam boyu öğrenme yeterliliklerine yönelik algılarını belirledikleri çalışmalarda, öğretmen adaylarının yaşam boyu öğrenmede kendilerini "yeterli" olarak algılamaları, araştırma sonucuyla paralellik göstermektedir. Bu bulgulara benzer olarak Karakuş (2013) meslek yüksekokulu öğrencilerinin yaşam boyu öğrenme yeterliklerinin iyi seviyede olduğu sonucuna ulaşmıştır. İzci ve Koç (2012) Sınıf, Matematik ve Türkçe öğretmen adaylarının yaşam boyu öğrenmeye ilişkin görüşlerini belirlemek amacıyla yaptıkları çalışmada; öğretmen adaylarının, yaşam boyu öğrenme konusunda güçlü bir duyarlıllğa sahip oldukları 
sonucuna ulaşmışlardır. Yılmaz (2016), araştırmasında öğretmenlerin yaşam boyu öğrenme eğilimlerinin yeterli düzeyde olduğu sonucuna ulaşmıştır.

Araştırmada öğretmen adaylarının yaşam boyu öğrenme becerilerinin ortalama puanın üzerinde olması önemli bir sonuç olmakla beraber yaşam boyu öğrenme eğilim düzeylerinin kısmen uyuyor çıkması öğretmen adaylarının bu becerileri kazanmada desteğe ihtiyaçlarının oldukları söylenebilir. Bu durumu Scheuch, Shouping ve Gaston (2009) öğretmen adayları temel becerilere sahip olabilirler ancak öğrenme yeteneklerinin istenilen boyutta olmadığını özellikle eğitim programlarının çok yönlü disiplinler arası olacak şekilde düzenlenmesi gerektiği şeklinde açıklamışlardır. Alanyazında araştırmanın ilgili sonucuyla paralellik göstermeyen araştırmalara da ulaşılmıştır. $\mathrm{Bu}$ araştırmalardan biri Diker Coşkun ve Demirel'in (2012) üniversite öğrencilerinin yaşam boyu öğrenme eğilimlerinin belirlendiği araştırmadır. İki farklı üniversitede öğrenim gören üniversite öğrencilerinin yaşam boyu öğrenme eğilimlerinin düşük olduğuna ilişkin elde edilen bulgu bu araştırma sonucuyla örtüşmemektedir. Tunca, Şahin ve Aydın (2015) tarafından yapılan bir başka araştırmada da üniversite öğrencilerinin yaşam boyu öğrenme eğilimlerinin düşük olduğu sonucuna ulaşılmıştır.

Araştırmada öğretmen adaylarının Yaşam Boyu Öğrenme Eğilimleri ölçeğinin motivasyon alt boyutundan aldıkları puanın yüksek düzeyde olduğu görülmüştür. Zorunlu olmasa da kendi istekleri doğrultusunda farklı öğrenmeler gerçekleştirme isteğinde oldukları özellikle yaşam boyu öğrenme isteği içerisinde oldukları yönde içsel motivasyona sahip oldukları söylenebilir (motivasyon=çok uyuyor). OECD (2000) raporuna göre motivasyonla yaşam boyu öğrenme arasında olumlu bir bağ vardır ve motivasyonu yüksek tutulan bireylerin hayatlarında öğrenmeyi de daha kolay sürdürebildikleri vurgulanmıştır. Alanyazında motivasyonla yaşam boyu öğrenme arasında bağ olduğuna ilişkin çalışmalar mevcuttur (Crow, 2006; Günüç, Odabaş1 ve Kuzu, 2012; OECD, 2000; Scales, 2008; Yelken ve Konakman, 2014; Tan ve Morris 2006).

Ölçeğin ilk iki boyutu yaşam boyu öğrenme isteği ve çabası ile ilgili duyuşsal öğrenme üzerinedir. Duyuşsal boyut bireylerin duyguları, inançları ve tutumlarının sosyal becerileriyle birleşimidir (Lang, 1998, s. 3). Lang'in belirttiği gibi bireyler sosyal beceri ve tutumların birleşimini olan duyuşsal öğrenmeleri gerçekleştirirken, öğrenme yaşantılarındaki olumlu ya da olumsuz deneyimler yaşam boyu öğrenmeye yönelik motivasyonlarını etkileyebilir. Araştırmada sınıf öğretmeni adaylarının yaşam boyu öğrenme motivasyonuna sahip oldukları ancak bu durumu farklı durumlara uyarlamada ve meraklarını sürdürme eğilimlerinin motivasyon ve sebat alt boyutlarına göre daha düşük düzeyde oldukları görülmüştür. Bu sonuç Tunca ve ark. (2015) tarafından gerçekleştirilen araştırma ve Diker Coşkun ve Demirel'in (2012) araştırma sonuçlarıyla benzerlik göstermektedir.

Araştırmada ölçeğin son iki boyutu olan öğrenmeyi düzenlemede yoksunluk ve merak yoksunluğu alt boyutlarında sınıf öğretmeni adaylarının aldıkları puan daha düşük düzeydedir. Buna göre sınıf öğretmeni adaylarının yaşam boyu öğrenme motivasyonuna sahip oldukları ancak bu durumu farklı durumlara uyarlamada ve meraklarını sürdürme eğilimlerinin düşük düzeyde oldukları söylenebilir. Bu durumu Tunca, Şahin ve Aydın (2015) öğretmen adaylarının zor ve farklı problemlerle karş1laştıklarında çaba gösterme düzeylerinin düşük olması ve bir şeyi öğrenme konusunda yeterince isteklerinin olmaması şeklinde açıklamıştır. 
Araştırmada sınıf öğretmeni adaylarının yaşam boyu öğrenme eğilimlerinin çeşitli değişkenlere göre karşılaştırılması incelenmiştir. Cinsiyete göre farklılaşıp farklılaşmadığına bakıldığında kadın öğretmen adaylarının yaşam boyu öğrenme eğilimlerinin, erkek öğretmen adaylarının yaşam boyu öğrenme eğilimlerinden daha yüksek olduğu bulunmuştur. Bu bulguya benzer olarak Gencel (2013) tarafından gerçekleştirilen araştırmanın sonuçlarına göre de kadın öğretmen adaylarının yaşam boyu öğrenme yeterliliklerine ilişkin algıları erkek öğretmen adaylarından daha olumludur. Bu durumu Jenkins (2004), bayanların sorumlulukları nedeniyle iş bırakma, iş değiştirme ya da işe ara verme vb. durumlarla sık karşılaştıklarını, değiş̧ime uyum sağlamak için çaba gösterdiklerini, böylelikle onların yaşam boyu öğrenme yeterliklerinin olumlu yönde etkilenmesi olarak açıklamaktadır (Akt: Gencel, 2013). İzci ve Koç (2012) da öğretmen adaylarının, yaşam boyu öğrenmeye ilişkin görüşlerde, kadın öğretmen adaylarının lehine anlamlı fark olduğu sonucuna ulaşmışlardır. Diker Coşkun (2009)'un gerçekleştirmiş olduğu araştırmada da kı öğrencilerin yaşam boyu öğrenme eğilimi daha yüksek düzeyde bulunmuştur. Jenkins (2004) yaşam boyu öğrenme kavramının özellikle kadınlar tarafından ihtiyaç duyulan bir özellik olduğunu ve genel olarak kadınların eğitim sisteminden erkekler kadar yararlanamadığını, bu nedenle temel eğitim açıklarını kapatmak için yaşam boyu öğrenme etkinliklerini daha fazla önemsediklerini belirtmiştir (Akt: Diker Coşkun ve Demirel, 2012). Alan yazında erkek öğretmen adaylarının kadın öğretmen adaylarına göre daha yüksek düzeyde yaşam boyu öğrenme eğilimine sahip olduğu( Diker Coşkun ve Demirel, 2012) araştırmalarda mevcuttur. Öte yandan cinsiyetin yaşam boyu öğrenme becerilerinde etkili bir değişken olmadığına dair farklı çalışmalar (Savuran, 2014; Şahin ve ark., 2010; Tunca ve ark., 2015; Yaman, 2014) vardır. Yaşam boyu öğrenme eğilimlerinin cinsiyete göre karşılaştırmalarda ortaya çıkan bu farklılıklar; araştırma yöntemi, örneklem grubunun farklılığından ya da cinsiyetin yaşam boyu öğrenme istekliliği ya da merakı açıklama konusunda genelleme yapmanın güçlüğünden kaynaklanıyor olabilir.

Sınıf öğretmeni adaylarının yaşam boyu öğrenme eğilimlerinde cinsiyete göre farklılık söz konusu iken mezun oldukları lise türünde anlamlı bir farklılık çıkmamıştır. Araştırmadan elde edilen bulgulara göre sınıf öğretmeni adaylarının yaşam boyu öğrenme eğilimlerinin çeşitli kurslara katılma durumlarına göre farklılık gösterdiği sonucuna ulaşılmıştır. Bu farklılık kursa katılanlar lehinedir. Ancak sınıf öğretmeni adaylarının katıldıkları kurs türüne göre yaşam boyu öğrenme eğilimleri değişmemektedir. Kurs türü fark etmeksizin öğretmen adaylarının farklı program ya da kurslarda yer almaları onların yaşam boyu öğrenme becerileri açısından önemli olduğu söylenebilir. Avrupa komisyonu 2006 yılında yaşam boyu öğrenmeyi bilgi, beceri ve yetenekleri geliştirmek amacıyla bireysel, sosyal ve iş ile ilgili yaşam boyunca yürütülen tüm öğrenme faaliyetleri olarak tanımlamıştır. Bu araştırma sonucuna göre de sınıf öğretmeni adayları bilgi, beceri ve yeteneklerini geliştirmek için farklı öğrenme faaliyetleri içerisindedirler diyebiliriz. Tan ve Morris (2006) yaşam boyu öğrenmeyi kişisel, mesleki ve sosyal gelişim olmak üzere üç bileşen üzerinden incelemiştir. Ancak yaşam boyu öğrenmede kişisel gelişimin diğer bileşenlerden daha önemli olduğunu vurgulamıştır. Çünkü Tan ve Morris'e (2006) göre kişinin her yaşam boyu öğrenme aşamasındaki çabaları kişisel gelişimini mutlaka etkileyecektir. $\mathrm{Bu}$ çalışmada da bireylerin örgün eğitim dışında farklı kurslara katılmaları onların yaşam boyu öğrenme eğilimlerini ve dolayısıyla gelişimlerini olumlu yönde etkilemektedir ancak kurs türleri açısından fark oluşturmamıştır. 


\section{Öneriler}

Araştırmada sınıf öğretmeni adaylarının yaşam boyu öğrenme eğilimleri ile kursa katılma durumları arasında anlamlı farklılık çıkmıştı. Öğretmen adaylarının yaşam boyu öğrenme eğilimlerini sağlamak için hem kişisel hem de mesleki gelişimleri açısından farklı kurslara yönlendirilebilir. Üniversite bünyesinde öğrencilerin gelişimlerine katkı sağlayacak sanatsal, sportif ve mesleki hayatlarına etki yapacak etkinlikler düzenlenebilir. Ayrıca araştırmanın nitel verilerle desteklenerek daha detaylı hale getirilebilir. Araştırma, daha büyük çalışma grupları üzerinde yapılabilir. 


\section{Kaynakça}

Akbaş, O. ve Özdemir, M. (2002). Avrupa birliğinde yaşam boyu öğrenme. Milli Ĕgitim Dergisi, (155156).

Arcuria, P. (2011). Assessing postsecondary students' orientation toward lifelong learning. Arizona: Arizona State Universty. (Master Thesis)

Atik K., D. ve Kürüm, D. (2007). Sınıf öğretmeni adaylarının yaşam boyu öğrenme kavramına yükledikleri anlam (Anadolu Üniversitesi örneği). Sözel bildiri, 16. Ulusal Eğitim Bilimleri Kongresi. Gaziosmanpaşa Üniversitesi, Tokat.

Can, T. (2011). Yaşam boyu öğrenme bağlamında yabancı dil olarak ingilizce ders kitaplarında strateji kullanımı. Yayımlanmamış doktora tezi. İstanbul Üniversitesi, Sosyal Bilimler Enstitüsü, İstanbul

Commission of the European Communities. (2000). A Memorandum on Lifelong Learning.

Brussels.http://www.bologna-berlin2003.de/pdf/MemorandumEng.pdf Erişim Tarihi: 04/04/2019.

Crow, S. R. (2006). What motivates a lifelong learner? School Libraries Worldwide, 12(1), 22-34.

Demirel, M, ve Akkoyunlu, B. (2010). Öğretmen adaylarının yaşam boyu öğrenme eğilimleri ve bilgi okuryazarlığ 1 özyeterlilik algıları. 10 th. International Educational Technology Conference, Boğaziçi Üniversitesi, İstanbul, Proceedings Book, 2, 1126- 1133.

Devlet Planlama Teşkilatı [DPT], (2001). Hayat boyu eğitim veya örgün olmayan eğitim özel ihtisas komisyon raporu. DPT Yay.

Diker Coşkun, Y. (2009). Üniversite ögrrencilerinin yaşam boyu öğrenme eğilimlerinin bazı değiş̧kenler açısından incelenmesi. Yayınlanmamış doktora tezi. Hacettepe Üniversitesi, Ankara.

Diker Coşkun, Y. ve Demirel, M. (2012). Üniversite Öğrencilerinin Yaşam Boyu Öğrenme Eğilimleri. Hacettepe Üniversitesi Eğitim Fakültesi Dergisi 42, 108-120

Epçaçan, C. (2013). Yaşam boyu öğrenme becerilerinin ders kitaplarında yer alma düzeyine örnek bir inceleme. Adiyaman Üniversitesi Sosyal Bilimler Enstitüsü Dergisi, 6(11), 353-379.

Faure, E., Herrera, F., Kaddoura, A. R., Lopes, H., Petrovsky, A. V., Rahnema, M. ve CHAMPION WARD, F. (1972). Learning to be. The world of education today and tomorrow, (Paris, UNESCO), http://unesdoc.unesco.org/images/0000/00001 8/001801E.pdf) Erişim Tarihi: 01/05/2019.

Field , J. (2001). "Lifelong education", International Journal of Lifelong Education, 20(1), 3-15.

Gencel, İ. E. (2013). Öğretmen adaylarının yaşam boyu öğrenme yeterliklerine yönelik algıları. Eğitim ve Bilim. 38(170), 237- 252.

Gündoğan, N. (2003). Avrupa Birliği'ne üye ülkelerde bir istihdam politikası aracı olarak yasam boyu öğrenme ve bazı örnek program ve uygulamalar. Kamu-IŞ Iş Hukuku Ve İktisat Dergisi. 7(2), 93108

Güngör, H. F. (2007). Avrupa birliği için yaşam boyu öğrenim temel yeterlikleri ve bu yeterliklerden "yabancı dillerde iletişim bağlamında Türkiye'nin durumu. Yayımlanmamış Yüksek lisans Tezi. Dokuz Eylül Üniversitesi Sosyal Bilimler Enstitüsü, İzmir

Günüç, S., Odabaşı, H. F. ve Kuzu, A. (2012). Yaşam boyu öğrenmeyi etkileyen faktörler. Gaziantep Üniversitesi Sosyal Bilimler Dergisi, 11(2), 309 -325.

İzci, E. ve Koç, S. (2012). Öğretmen adaylarının yaşam boyu öğrenmeye ilişkin görüşlerinin değerlendirilmesi. Adlyaman Üniversitesi Sosyal Bilimler Enstitüsü Dergisi, 5 (9), 101-114.

Karakuş, C. (2013). Meslek yüksek okulu öğrencilerinin yaşam boyu öğrenme yeterlikleri. Journal of Research in Education and Teaching, 2(3), 26-35.

Karasar, N. (2007). Bilimsel araştırma yöntemi. Ankara: Nobel Yayın Dă̆ıtım. 
Kılıç, H. ve Tuncel, A. Z. (2014). İlköğretim branş öğretmenlerinin bireysel yenilikçilik düzeyleri ve yaşam boyu öğrenme eğilimleri. Uluslarası Eğitim Programları ve Öğretim Çalışmaları Dergisi, $4(7), 25-37$.

Lang, P. (1998). Towards an Understanding of Affective Education in a European Context, Affective Education: A Comparative View, (Ed. Peter Lang, Yaacov Katz ve Isabel Menezes), Published by Continuum International Publishing Group. 3-16.

MEB. (2009). Türkiye Hayat Boyu Öğrenme Strateji Belgesi. http://metek.meb.gov.tr/dosyalar/Turkiye.HAYAT.BOYU.\%20OGRENME.STRATEJI.BELGE

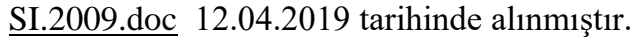

OECD. (2000). Motivating students for lifelong learning. What Works in Innovation in Education Series, OECD, Paris.

Parker, S. (2003). Research Briefing: Widening participation and Lifelong Learning - Some theoretical and practical considerations www.kent.ac.uk/uelt/academicpractice/docs/researchbriefing.pdf Erişim Tarihi: 04/04/ 2019.

Rausch, A. (2003). A case study of lifelong learning in Japan: Objectives, curriculum, accountability and visibility. International Journal of Lifelong Education, 22(5), 518-532.

Savuran, Y. (2014). İngilizce öğretmen adaylarının mentorlarına klyasla yaşam boyu öğrenme becerileri. Yayımlanmamış Yüksek Lisans Tezi, Hacettepe Üniversitesi, Eğitim Bilimleri Enstitüsü, Ankara

Scales, P. (2008). Teaching in the lifelong learning sector. Buckingham: GBR: Open University Press.

Scheuch, K., Shouping H. ve Gaston, G.J. (2009). The influences of faculty on undergraduate student participation in research and creative activities. Innovative Higher Education, 34(3), 173-183.

Selvi, K. (2011). Teachers' Lifelong learning competencies. International Journal of Curriculum and Instructional Studies, 1(1), 61-69.

Şahin, M., Akbaşlı, S. ve Yanpar-Yelken, T. (2010). Key competences for lifelong learning: The case of prospective teachers. Educational Research and Review, 5(10), 545-556.

Şişman, M. ve Acat, B. M. (2003). Öğretmenlik uygulaması çalışmalarının öğretmenlik mesleğinin algılanmasındaki etkisi. Firat Üniversitesi Sosyal Bilimler Dergisi, 13(1), 235-250.

Tan, C. L. ve Morris, J. S. (2006). Undergraduate college students, laptop computers, and lifelong learning. The Journal of General Education, 54(4), 316-338.

Tunca, N., Şahin, S. ve Aydın; Ö.(2015). Öğretmen adaylarının yaşam boyu öğrenme eğilimleri. Mersin Üniversitesi Ĕ̈itim Fakültesi Dergisi, 11(2). 432-446.

Yelken, T. ve Konakman, G. (2014). Eğitim fakültesi öğretim elemanlarının yaşam boyu öğrenme yeterliklerine ilişkin algıları. Hacettepe Üniversitesi Eğitim Fakültesi Dergisi, 29(2), 267-281.

Yaman, F. (2014). Öğretmenlerin yaşam boyu öğrenme eğilimlerinin incelenmesi (Diyarbakır il örneği). Yayınlanmamış Yüksek Lisans Tezi, Dicle Üniversitesi Eğitim Bilimleri Enstitüsü, Diyarbakır.

Yılmaz, M. (2016). Öğretmenlerin yaşam boyu öğrenme eğilimlerinin incelenmesi. Mustafa Kemal Üniversitesi Sosyal Bilimler Enstitüsü Dergisi, 13(35), 253-262. 


\section{Extended Abstract}

\section{Introduction}

The concept of Lifelong Learning was first included in the Education Act in England in 1919, however it was more explicitly and comprehensively addressed in the Report of the International Commission on the Development of Education by the United Nations Educational, Scientific and Cultural Organization (UNESCO) in 1972. (Field 2001; Parker, 2003). The concept of lifelong learning appeared in a report by OECD in Turkey and was described as occupational mobility and individual learning within the framework of global economy (DPT, 2001). Lifelong learning is defined as "any kind of learning activity that an individual has participated in throughout his life in order to improve his knowledge, skills, interests and competences with a personal, civic, social and employment-related perspective" in the Turkish Lifelong Learning Strategy Paper published by the Ministry of Education (2009) (p. 7).

Lifelong learning has started with professional development but has taken shape as an activity for individuals who have not stopped learning. It is teachers who will carry out learning how to learn and lifelong learning skills. Teachers are involved in this process and their own lifelong learning competences become prominent as well. According to Selvi (2011), teachers' lifelong learning competences should comprise two key elements, including professional development skills and their responsibilities and roles in students' becoming lifelong learners. Therefore, whether teachers have these competences depends primarily on the university education they receive, namely the professional education processes. It is of particular importance that primary school teachers, who will first arouse and develop the curiosity and enthusiasm for learning in children, have lifelong learning skills. This study aimed to reveal whether the lifelong learning tendencies of primary school teacher candidates differed in terms of gender, the type of high school they graduated, their participation in courses and the type of course they attended. For this purpose, answers to the following sub-problems were sought:

1. What is the level of the lifelong learning tendencies of primary school teacher candidates?

2. Do the lifelong learning tendencies of primary school teacher candidates differ by their gender?

3. Do the lifelong learning tendencies of primary school teacher candidates differ by the type of high school they graduated?

4. Do the lifelong learning tendencies of primary school teacher candidates differ by their participation in courses?

5. Do the lifelong learning tendencies of primary school teacher candidates differ by the type of course they attended?

\section{Methodology}

The research was carried out through the general survey model, which is one of the survey models. The sample consisted of $1554^{\text {th }}$ grade students studying at the Department of Elementary Education in the Faculty of Education of Pamukkale University. All the universe of the study was tried to be reached. The data of the study were collected through the "Lifelong Learning Tendency Scale" developed by Diker Çoşkun (2009). The 27-item scale consisted of two parts: personal information and scale items. Considering the general mean score of the 
scale, the minimum score that can be obtained from the scale was calculated as $(27 \times 1) 27$, the median score as $(27 \times 3,5) 94,5$ and the maximum score as $(27 \times 6) 162$. T-test was used to compare the mean scores obtained from the scale according to the variables.

\section{Results and Discussion}

Lifelong learning tendencies of primary school teacher candidates were examined in four subdimensions: motivation, perseverance, lack of self-regulation and lack of curiosity. According to the results of the research, the lifelong learning tendency scores of the teacher candidates were above the mean score of the scale. Although the fact that the teacher candidates' lifelong learning skills were above the average score is an important result, it can be suggested that the teacher candidates need support to gain these skills considering that their lifelong learning tendency levels partially fit. Scheuch, Shouping and Gaston (2009) argue that pre-service teachers may have the basic skills, but their learning skills are not at the desired level, and especially instructional programs should be designed in a multidirectional and interdisciplinary way. In the study, it was observed that the scores of the teacher candidates in the sub-dimension of motivation of the Lifelong Learning Tendency scale were high. It can be put forward that they had intrinsic motivation in that they wanted to have different learning, especially lifelong learning voluntarily. In addition, it was found out that the teacher candidates had lifelong learning motivation but their tendencies to adapt this situation to different situations and to sustain their curiosity were lower than the sub-dimensions of motivation and perseverance. In the study, the lifelong learning tendencies of the primary school teacher candidates were compared in terms of different variables. While the lifelong learning tendencies of primary school teacher candidates differed by gender, no significant difference was revealed in terms of the type of high school they graduated.

It was also concluded that the lifelong learning tendencies of primary school teacher candidates differed by their participation in various courses. This difference was found to be in favour of the candidates participating in courses. However, the lifelong learning tendencies of primary school teacher candidates did not differ by the type of the course they attended. Regardless of the type of the course, it can be maintained that teacher candidates' participation in different programs or courses is important for their lifelong learning skills. In 2006, the European Commission defined lifelong learning as all kinds of learning activities undertaken throughout one's life related to personal, social and work life to develop knowledge, skills and competences. According to the results of the present study, it can be stated that primary school teacher candidates are involved in different learning activities to improve their knowledge, skills and abilities.

In the study, a significant difference was revealed between the lifelong learning tendencies of the primary school teacher candidates and their participation in courses. Teacher candidates can be directed to different courses for their personal and professional development to ensure their lifelong learning tendencies. Activities that will contribute to the development of students and affect their artistic, sportive and professional lives can be organized at university. In addition, the study can be supported with qualitative data, thus making it more detailed. Also, the study can be conducted on a larger sample. 